\title{
Outcome of out-of-hospital cardiopulmonary arrest in children: A multicenter cohort study
}

\author{
Funda Kurt ${ }^{1}$, Tanıl Kendirli ${ }^{3}$, Ramiz Coskun Gündüz ${ }^{4}$, Selman Kesici ${ }^{5}$, Halise Akça ${ }^{6}$, \\ Şanlıay Şahin ${ }^{4}$, Gökhan Kalkan ${ }^{7}$, Murat Derbent ${ }^{8}$, Nilden Tuygun ${ }^{6}$, Çağlar Ödek ${ }^{3}$, \\ Ayşe Gültekin-Keser ${ }^{9}$, Sinan Oğuz², Emine Polat ${ }^{11}$, Okşan Derinöz ${ }^{10}$, Deniz Tekin², \\ Özlem Tekşam ${ }^{9}$, Benan Bayrakc1 ${ }^{5}$, Emine Suskan ${ }^{2}$ \\ ${ }^{1}$ Division of Pediatric Emergency Medicine, ${ }^{4}$ Department of Pediatrics, Ankara Children's Hematology Oncology Training \\ and Research Hospital; ${ }^{2}$ Division of Pediatric Emergency Medicine, ${ }^{3}$ Division of Pediatric Intensive Care Unit, Department \\ of Pediatrics, Ankara University Faculty of Medicine; ${ }^{5}$ Division of Pediatric Intensive Care Unit, ${ }^{9}$ Division of Pediatric \\ Emergency Medicine, Department of Pediatrics, Hacettepe University Faculty of Medicine; ${ }^{6}$ Division of Pediatric Emergency \\ Medicine, ${ }^{11}$ Department of Pediatrics, Dr Sami Ulus Maternity and Children's Health and Diseases Training and Research \\ Hospital; ${ }^{7}$ Division of Pediatric Intensive Care Unit, ${ }^{10}$ Division of Pediatric Emergency Medicine, Gazi University Faculty \\ of Medicine; ${ }^{8}$ Division of Pediatric Emergency Medicine, Başkent University Faculty of Medicine, Ankara, Turkey. E-mail: \\ drfundakurt@gmail.com
}

Received: 2nd March 2017, Revised: 9th December 2017, Accepted: 24th December 2017

SUMMARY: Kurt F, Kendirli T, Gündüz RC, Kesici S, Akça H, Şahin Ş, Kalkan G, Derbent M, Tuygun N, Ödek Ç, Gültekin-Keser A, Oğuz S, Polat E, Derinöz O, Tekin D, Tekşam Ö, Bayrakcı B, Suskan E. Outcome of outof-hospital cardiopulmonary arrest in children: A multicenter cohort study. Turk J Pediatr 2018; 60: 488-496.

The aim of this study was to evaluate the demographic characteristics of children who experienced out-of-hospital cardiopulmonary arrest (CPA), and to assess the impact of the bystander cardiopulmonary resuscitation (CPR) on the survival rate of witnessed arrests and the effects of the arrest and CPR durations on the neurological outcomes. This multicenter, retrospective study included a total of 182 patients who underwent CPR for out-of-hospital CPA between January 2008 and December 2012 at six centers in Ankara, Turkey. The median [interquartile range (IQR)] age was 22 (5-54) months; $60.4 \%$ of the patients were males, and $44 \%$ were younger than one year of age. The witnessed arrest rate was $75.8 \%(138 / 182)$ and the rate of bystander CPR was $13.9 \%$ (13/93). In these patients the rate of the return of spontaneous circulation (ROSC) was higher $(76.9 \%)$. Following resuscitation in the patients for whom the spontaneous circulation was able to be returned, the median (IQR) duration of arrest was 5 (1- 15) $\mathrm{min}$, while it was $15(5-40) \mathrm{min}$ for the remaining patients $(\mathrm{p}<0.001)$. The ROSC rate was $94.9 \%$ in patients who underwent CPR for less than $20 \mathrm{~min}$ and $22 \%$ in patients requiring CPR longer than $20 \mathrm{~min}(\mathrm{p}<0.001)$. Survival to hospital discharge was $14.3 \%$. Of these patients, $57.7 \%$ experienced neurological disability. The short duration of an arrest and the presence of CPR are both critical for survival. We suggest that a witness to the CPA, performing early and efficient CPR, yields better results.

Key words: cardiac arrest, cardiopulmonary resuscitation, pediatrics, out-of-hospital.

The out-of-hospital cardiopulmonary arrest (CPA) is a rare, but serious condition in children, as its mortality rate is high and it may lead to serious neurological sequelae in surviving patients. ${ }^{1-3}$ Incidence of pediatric out-of-hospital CPA is reported to be between six and 19/100,000 person-year with a survival rate of two to $24 \% .{ }^{4-8}$
Due to the positive results achieved in adults, pediatric studies are currently the focus of concentration. ${ }^{9}$ Between 30 and $50 \%$ of pediatric out-of-hospital CPA cases comprise infants less than one year of age. ${ }^{4-6}$ In previous studies, the incidence and the mortality rate were reported to be much higher in children of less than one year of age, compared to those 
aged between 1 and 12 years and adolescents (aged between 12 and 18 years).5,10

The majority of CPA cases occur in the non-public setting, such as home. The most common cause in the etiology of out-of-hospital CPA is respiratory, and the initially recorded cardiac rhythm is typically asystole/pulseless electrical activity (PEA).5,9 Children whose arrest is witnessed and receive bystander cardiopulmonary resuscitation (CPR) have improved neurological outcomes. Bystander CPR is given in only 15 to $40 \%$ of pediatric patients. 4,10 Earlier CPR is associated with improved neurological outcomes, while prolonged periods of no-flow may result in neurological sequelae in most of the surviving patients.

To date, there have been no multi-center studies in children experiencing out-of-hospital CPA in Turkey. In this study, we aimed to evaluate the demographic characteristics of children who experienced out-of-hospital CPA, and to assess the impact of the bystander CPR on the survival rate of witnessed arrests and the effects of the arrest and CPR durations on the neurological outcomes.

\section{Material and Methods}

This multi-center, descriptive, retrospective study was conducted between January 2008 and December 2012 in the pediatric emergency and pediatric intensive care units of university hospitals and training and research Hospitals in Ankara. Children aged between one month and 18 years who experienced out-of-hospital CPA and underwent chest compression for at least one minute were included in the study.

The study protocol was approved by the Ethical Committee. The study was conducted in accordance with the principles of the Declaration of Helsinki.

By using the medical records of the patients in six centers, the following data were recorded: demographic characteristics including age, sex, and presence of underlying chronic disorder; the event features, including the arrest location, arrest duration, arrest day (weekday-weekend), whether the arrest was witnessed and if witnessed, who the witness was (healthcare personnel, family), was CPR performed by the person who witnessed the event, the initial location of resuscitation (i.e., home, outside, ambulance) and the first detected rhythm in the patient (asystole, bradycardia, PEA, ventricular fibrillation (VF), pulseless ventricular tachycardia (VT), unidentified); the etiology of the arrest, including respiratory failure (upper airway disease, pulmonary disease, hypoventilation), circulatory failure, central nervous system disease, poisoning, and trauma; the interventions performed, including airway management (mouth to mouth, bagmask, intubation) and drugs used (epinephrine, sodium bicarbonate, lidocaine, amiodarone, calcium, glucose, atropine, fluids).

The medical records were also used to identify how the patients were delivered to hospital. In Turkey, when individuals require pre-hospital emergency health care, the emergency medical service (EMS) phone number, 112, is called and help is requested. An ambulance and medical intervention (usually paramedics) is sent to the patient in the shortest possible time, and the patient is taken to hospital. In the present study, EMS ambulances transported some of our patients, while others were taken to hospital by their relatives.

Arterial blood gas measurements, the mean resuscitation time, the mean number of days under mechanical ventilation, the number of the patient's arrests until discharge from hospital, and the length of hospital stay were recorded in the patients whose spontaneous circulation returned following resuscitation.

In all patients whose spontaneous circulation returned following the initial resuscitation, a Glasgow Coma Score was obtained within the first three hours to assess their neurological status. The Pediatric Cerebral Performance Scale (PCPC) was performed on patients whose spontaneous circulation returned following resuscitation and were discharged from hospital. PCPC scores measure the degree of cognitive function and range from 1 to 6 , where 1 is normal, 2 is mild disability, 3 is moderate disability, 4 is severe disability, 5 is coma or vegetative state, and 6 is brain death. The score of 1-2 indicate good neurological status, while 3-5 indicate poor neurological status. ${ }^{11}$

\section{Statistical Analysis}

Statistical analysis was performed using the 
Table I. Description of Pediatric Cardiac Arrest Victims $(n=182)$.

\begin{tabular}{|c|c|c|c|}
\hline Factor & Variable & $\mathrm{n}$ & $(\%)$ \\
\hline \multicolumn{4}{|c|}{ Age category } \\
\hline & $>1$ month-1 year & 80 & $(44.0 \%)$ \\
\hline & $1-12$ years & 80 & $(44.0 \%)$ \\
\hline & $13-18$ years & 22 & $(12.0 \%)$ \\
\hline \multicolumn{4}{|c|}{ Gender } \\
\hline & Male & 110 & $(60.4 \%)$ \\
\hline & Female & 72 & $(39.6 \%)$ \\
\hline \multicolumn{4}{|c|}{ Arrest site } \\
\hline & Home & 97 & $(53.3 \%)$ \\
\hline & Outside & 35 & $(19.2 \%)$ \\
\hline & During transport & 50 & $(27.5 \%)$ \\
\hline \multicolumn{4}{|c|}{ Witness status } \\
\hline & Witnessed bystander & 93 & $(51.1 \%)$ \\
\hline & Witnessed- EMS & 45 & $(24.7 \%)$ \\
\hline & Not witnessed & 44 & $(24.2 \%)$ \\
\hline \multicolumn{4}{|c|}{ Type of admission to the } \\
\hline & EMS & 99 & $(54.4 \%)$ \\
\hline & With their own means & 83 & $(45.6 \%)$ \\
\hline \multicolumn{4}{|c|}{ Time of arrest } \\
\hline & 08:00-16:59 & 82 & $(45.1 \%)$ \\
\hline & $17: 00-07: 59$ & 100 & $(54.9 \%)$ \\
\hline \multicolumn{4}{|c|}{ Day of arrest } \\
\hline & Weekday & 130 & $(71.4 \%)$ \\
\hline & Weekend & 52 & $(28.6 \%)$ \\
\hline \multicolumn{4}{|c|}{ Causes of Cardiac Arrest } \\
\hline & Respiratory failure & 100 & $(55.0 \%)$ \\
\hline & Circulatory failure & 38 & $(20.9 \%)$ \\
\hline & CNS disease & 30 & $(16.5 \%)$ \\
\hline & Trauma & 11 & $(6.0 \%)$ \\
\hline & Poisoning & 3 & $(1.6 \%)$ \\
\hline
\end{tabular}

CNS: central nervous system; EMS: emergency medical service.

SPSS (Statistical Package for Social Sciences) for Windows 20 (SPSS Inc., Chicago, IL, USA) program. Normal distribution of data was evaluated with the Kolmogorov-Smirnov normality tests. Normally distributed variables were expressed in mean $\pm \mathrm{SD}$, while abnormally distributed variables were expressed in median (Interquartile range). The Mann-Whitney U-test was used to compare abnormally distributed variables between two groups. The Pearson chi-square test was used to compare categorical variables. A $p$ value of $<0.05$ was considered statistically significant.

\section{Results}

During the study period, CPR was performed on 182 cases with out-of-hospital CPA. The patients' characteristics and descriptions are presented in Table I. Of all patients, 80 (44\%) were less than 12 months old, while $60.4 \%$ were males. Ninety-seven $(53.3 \%)$ events occurred in the home setting. The majority, 138 (75.8\%) of the patients, were witnessed. Of these $51.1 \%$ were witnessed by a bystander and $24.7 \%$ by EMS. Of the 182 cases, $83(45.6 \%)$ were delivered to the hospital independently. 
In addition, CPA most commonly (54.9\%) occurred at night - from 5:00 PM to 7:59 AM. The weekday arrest rate was 130 (71.4\%), while the weekend rate was $52(28.6 \%)$. The most frequent cause of arrest was respiratory failure with 100 patients (55\%).

Table II shows the patients' characteristics in relation to the outcome of CPR. Return of spontaneous circulation (ROSC) was achieved in 83 cases $(45.6 \%)$ and not achieved in 99 cases $(54.4 \%)$. The median (IQR) age was 22 (5-54) months. One hundred cases $(61.0 \%)$ had chronic pre-existing conditions. In these cases, spontaneous circulation was unable to be returned $(p=0.053)$. In both groups, the age, sex, and frequency of chronic conditions were similar.

Arrest characteristics are described in Table III. The return of spontaneous circulation was achieved in $74.7 \%$ of the cases who experienced CPA on a weekday, and in $25.3 \%$ at the weekend $(p=0.413)$. The patients for whom spontaneous circulation was unable to be achieved $37.4 \%$, were admitted during the daytime, while $62.6 \%$ were admitted at night $(p=0.053)$. Of the patients for whom spontaneous circulation were able to be returned, $70(84.3 \%)$ were witnessed and $13(15.7 \%)$ were not; whereas, of those for whom spontaneous circulation did not return $68(68.7 \%)$ were witnessed and 31 $(31.3 \%)$ were not $(p=0.015)$. In ten $(12.1 \%)$ of the patients for whom spontaneous circulation was achieved, resuscitation was carried out by bystanders; whereas, in $73(87.9 \%)$, it was given by the EMS personnel $(p=0.022)$. In the cases of out-of-hospital CPA, who were admitted to the hospital by their relatives, the rate of ROSC was 30 (36.1\%), whereas, in the cases transferred to the hospitals by EMS, the rate was $53(68.9 \%)(p=0.025)$. The initially identified rhythm was asystole in 116 cases, bradycardia in 39 cases, and VT/VF in four. The rhythm was not specified in 23 cases. The ROSC was found in $31 \%$ of the patients for whom the initially identified rhythm was asystole, in $79.5 \%$ of those with bradycardia, and in $75 \%$ of those with VT/VF $(p<0.001)$

Table II. Outcome of CPR and Patients' Characteristics.

\begin{tabular}{|c|c|c|c|c|c|c|}
\hline & \multirow{3}{*}{$\begin{array}{c}\text { Total arrests } \\
\mathrm{n}=182\end{array}$} & \multicolumn{4}{|c|}{ Success (ROSC } & \multirow[b]{3}{*}{$\mathrm{p}$ value } \\
\hline & & \multicolumn{2}{|c|}{$\begin{array}{c}\text { Achieved } \\
\mathrm{n}=83(45.6 \%)\end{array}$} & \multicolumn{2}{|c|}{$\frac{\text { Not achieved }}{n=99(54.4 \%)}$} & \\
\hline & & $\mathrm{n}$ & $\%$ & $\mathrm{n}$ & $\%$ & \\
\hline \multicolumn{7}{|l|}{ Age (month) } \\
\hline Median (IQR) & $22(5-54)$ & $24(5-72)$ & & $18(6-48)$ & & $0,368^{*}$ \\
\hline Range & $1-216$ & $1-204$ & & $1-216$ & & \\
\hline $1-12 \mathrm{mo}$ & 80 & 34 & 42.5 & 46 & 57.5 & $0.380^{* *}$ \\
\hline $13-144 \mathrm{mo}$ & 80 & 36 & 45.0 & 44 & 55.0 & \\
\hline $145-216 \mathrm{mo}$ & 22 & 13 & 59.1 & 9 & 40.9 & \\
\hline Gender & & & & & & $0.447^{* *}$ \\
\hline Male & 110 & 53 & 48.2 & 57 & 51.8 & \\
\hline Female & 72 & 30 & 41.7 & 42 & 58.3 & \\
\hline $\begin{array}{l}\text { Any chronic pre-existing } \\
\text { condition }\end{array}$ & 100 & 39 & 39.0 & 61 & 61.0 & $0.053^{* *}$ \\
\hline \multicolumn{7}{|l|}{ Pre-existing conditions } \\
\hline Lung or airway disease & 5 & 3 & 60.0 & 2 & 40.0 & \\
\hline Heart disease & 25 & 11 & 44.0 & 14 & 56.0 & \\
\hline Hematological & 6 & 2 & 33.3 & 4 & 66.7 & \\
\hline Metabolic & 25 & 5 & 20.0 & 20 & 80.0 & \\
\hline Neurological & 39 & 18 & 46.2 & 21 & 53.8 & \\
\hline
\end{tabular}

ROSC: Return of spontaneous circulation; IQR: interquartile range

* Mann-Whitney U Test ** Chi-square Test 


\section{(Table III).}

We also found that mouth-to-mouth breathing was used in six $(3.3 \%)$ patients, bag-mask ventilation in $21(11.5 \%)$ patients, and endotracheal intubation in $155(85.2 \%)$ patients for maintaining the airway during resuscitation. Almost all of these patients $(98.7 \%, n=153)$ were intubated at emergency services. The airway management given by EMS personnel was maintained by bag-mask. The ROSC was present in 68 patients $(46.3 \%)$ who were administered fluid bolus and in 79 patients (53.7\%) for whom spontaneous circulation was unable to be returned $(p=0.717)$. All patients $(100 \%, n=182)$ received epinephrine during resuscitation. Drugs used during arrest are shown in Table III.

Following resuscitation in the patients for whom the spontaneous circulation were able to be returned, the median (IQR) duration of arrest was 5 (1-15) min, while it was 15 (540) $\mathrm{min}$ for the remaining patients $(p<0.001)$. In the patients with a resuscitation period of less than $20 \mathrm{~min}$, the spontaneous circulation returned in $94.9 \%$ and did not return in $5.1 \%$. In the patients with a resuscitation period longer than $20 \mathrm{~min}$, the spontaneous circulation returned in $22.0 \%$ and did not return in $78.0 \%$ $(p<0.001)$ (Table III).

\section{Laboratory Data and Organ Dysfunction}

The median (IQR) duration of using mechanical ventilator $(\mathrm{MV})$ was found to be $6(2-16)$ days and the length of hospital stay as 6 (1-27) days in ROSC patients. Following CPR, there was respiratory failure in $55(66.3 \%)$, cardiovascular failure in $51(61.4 \%)$, neurological dysfunction in $50(60.2 \%)$, liver injury in $27(32.5 \%)$, hematological dysfunction in $26(31.3 \%)$ and renal injury in 23 patients $(27.7 \%)$.

Following CPR, 68 (67.5\%) of the 83 surviving patients were comatose with a median (IQR) GCS score of 3 (3-4). Neuroprotective therapies, such as temperature-targeted management (TTM), were utilized in 16 patients (19.3\%). Hypertonic saline was given to 16 patients (19.3\%); mannitol to 12 patients $(14.5 \%)$, and steroids to 12 patients (14.5\%).

In certain patients, CPR was performed more than once. The number of patients undergoing CPR twice was 36; seven underwent CPR three times, and three had CPR four times. The survival rate was very low in patients who underwent CPR two or more times $(p<0.001)$.

\section{Outcome}

Of all patients, $26(14.3 \%)$ were discharged from hospital. In 24 (92.4\%) of the discharged patients, the arrest was witnessed. The median (IQR) length of hospital stay was 37 (15.355.3) days in survivors.

Among 26 patients who were discharged home, seven (26.9\%) had good PCPC scores; four $(15.4 \%)$ had no change compared to the previous abnormal neurological status, and $15(57.7 \%)$ had a poor outcome (PCPC score 3-5). One of the six patients with brain death also became an organ donor.

We found that there was no statistically significant difference in comparison of arrest and duration of CPR in patients discharged home with good or poor neurological status $(\mathrm{p}=0.061, \mathrm{p}=0.198$, respectively).

\section{Discussion}

Out-of-hospital CPA is an unusual occurrence in children. ${ }^{5,8}$ Despite the CPR guidelines developed for the treatment of children within the past three decades, the results are still underwhelming. ${ }^{9}$ In our study, similar to others, the survival rate was found to be low. VF was very rare as the initially identified rhythm, most of the arrests occur at home, and the rate of bystander CPR was low. The rate of ROSC also increases when the CPR is performed by the witness; however, the survival rate remains unchanged. In this study, patients undergoing CPR for longer than 20 min duration had poor neurological sequelae with a low survival rate.

The demographic data in this study were similar to other studies among out-of-hospital CPA cases. In many studies, 30 to $50 \%$ of patients were aged less than one year. The significantly high rate in this age group is associated with sudden infant death syndrome.4, 6, 10,12,13 In our study, we showed that $44.0 \%$ of our cases were less than one year of age. Similar to previous studies, it was more frequent amongst the male sex. $.7,8,12,14,15$ In addition, most of the arrests occurred at home, consistent with the previous reports. $5,7,9,12,14,15$

In addition, the patients in our study were delivered to the hospitals either by their 
Table III. Cardiac Arrest Event Characteristics and Relationship to ROSC.

\begin{tabular}{|c|c|c|c|c|}
\hline & \multirow{3}{*}{$\begin{array}{l}\text { Total arrests } \\
\mathrm{n}=182\end{array}$} & \multicolumn{2}{|c|}{ Success (ROSC } & \multirow[b]{3}{*}{$\mathrm{p}$ value } \\
\hline & & $\frac{\text { Achieved }}{\mathrm{n}=83(45.6 \%)}$ & $\frac{\text { Not achieved }}{\mathrm{n}=99(54.4 \%)}$ & \\
\hline & & $\mathrm{n}(\%)$ & n $(\%)$ & \\
\hline $\begin{array}{l}\text { Day of arrest (if unavailable, using CPR, } \\
\text { ROSC, or arrival at hospital) }\end{array}$ & & & & $0.413^{*}$ \\
\hline Weekday & 130 & $62(74.7)$ & $68(68.7)$ & \\
\hline Weekend & 52 & $21(25.3)$ & $31(31.3)$ & \\
\hline $\begin{array}{l}\text { Time of arrest (if unavailable, using CPR, } \\
\text { ROSC, or arrival at hospital)b }\end{array}$ & & & & $0.053^{*}$ \\
\hline Day (08:00-16:59) & 80 & $43(51.8)$ & $37(37.4)$ & \\
\hline Night (17:00-07:59) & 102 & $40(48.2)$ & $62(62.6)$ & \\
\hline \multicolumn{5}{|l|}{ Witness status ${ }^{b}$} \\
\hline Witnessed & 138 & $70(84.3)$ & $68(68.7)$ & $0.015^{*}$ \\
\hline Not witnessed & 44 & $13(15.7)$ & $31(31.3)$ & \\
\hline The initial resuscitator ${ }^{b}$ & & & & $0.022^{*}$ \\
\hline Non-health person & 13 & $10(12.1)$ & $3(3.0)$ & \\
\hline Health care personnel & 169 & $73(87.9)$ & $96(97.0)$ & \\
\hline Type of delivery to the hospital ${ }^{b}$ & & & & $0.025^{*}$ \\
\hline EMS & 99 & $53(68.9)$ & $46(46.5)$ & \\
\hline Patient relatives & 83 & $30(36.1)$ & $53(53.5)$ & \\
\hline First monitored rhythm ${ }^{a}$ & & & & $<0.001^{*}$ \\
\hline Asystole & 116 & $36(31.0)$ & $80(69.0)$ & \\
\hline Bradycardia & 39 & $31(79.5)$ & $8(20.5)$ & \\
\hline $\begin{array}{l}\text { Ventricular fibrillation/ } \\
\text { tachycardia }\end{array}$ & 4 & $3(75.0)$ & $1(25.0)$ & \\
\hline Other / Unknown & 23 & $13(56.5)$ & $10(43.5)$ & \\
\hline \multicolumn{5}{|l|}{$\begin{array}{l}\text { Drugs administered during arrest except } \\
\text { Adrenalin }^{\mathrm{a}}\end{array}$} \\
\hline Fluid bolus & 147 & $68(46.3)$ & $79(53.7)$ & $0.717^{*}$ \\
\hline Atropine & 23 & $10(43.5)$ & $13(56.5)$ & $0.827^{*}$ \\
\hline Sodium bicarbonate & 114 & $35(30.7)$ & $79(69.3)$ & $<0.001^{*}$ \\
\hline Calcium & 15 & $6(40.0)$ & $9(60.0)$ & $0.649^{*}$ \\
\hline Lidocaine & 3 & $2(66.7)$ & $1(33.3)$ & $0.593^{*}$ \\
\hline Amiodarone & 3 & $3(100.0)$ & 0 & $0.093^{*}$ \\
\hline Glucose & 11 & $2(18.2)$ & $9(81.8)$ & $0.069^{*}$ \\
\hline The duration of arrest [Median (IQR)] & $10(1-28.8)$ & $5(1-15)$ & $15(5-40)$ & $<0.001^{* *}$ \\
\hline \multicolumn{5}{|l|}{ The duration of CPR } \\
\hline Median (IQR) & $30(20-45)$ & $15(10-25)$ & $40(30-45)$ & $<0.001^{* *}$ \\
\hline $1-20 \mathrm{~min}$ & 59 & $56(94.9)$ & $3(5.1)$ & $<0.001^{*}$ \\
\hline$>20 \mathrm{~min}$ & 123 & $27(22.0)$ & $96(78.0)$ & \\
\hline
\end{tabular}

CPR: cardiopulmonary resuscitation; EMS: emergency medical service; ROSC: return of spontaneous circulation; SD: standard deviation; IQR: interquartile range.

araw percentages given, ${ }^{b}$ column percentages given

* Chi-square Test ** Mann-Whitney U Test 
relatives or by EMS. Fifty-three patients (63.9\%) delivered by their families did not survive; this result was considered to be related to the longer duration of arrest, compared to the patients admitted through EMS.

In their study, Gerein et al. ${ }^{8}$ determined a rate of $30 \%$ for chronic disorders; in our study, the ratio of underlying disorders was $54.9 \%$. In children with underlying disorders, even a simple problem may lead to the disturbance of balance and rapid impairment of the overall condition. Therefore, the increased risk of out-of-hospital CPA is an expected outcome in patients with underlying disorders.

In a study, Kitamura et al. ${ }^{16}$ reported that the ROSC rate was lower in nighttime arrests. We also found that the ROSC rate was lower at nighttime. This can be attributed to the fact that arrests occurring at night are able to be diagnosed and managed in a delayed fashion.

Several studies have reported survival rates of between 2 and 24\%.6, 8, 24-27 In the study of Kendirli et al. ${ }^{28}$, ROSC was found in 10 (41.7\%) of 24 out-of-hospital CPA cases and only two (8\%) were discharged from hospital. In South Korea, the outcomes of pediatric out-of-hospital CPA cases have improved in the past five years; the ROSC rate following CPR was reported to increase from $17.6 \%$ to $35.2 \%$ and the discharge rate from $4.4 \%$ to $12.8 \% .^{14,29}$ The ROSC was obtained in 83 patients $(45.6 \%)$, following the initial CPR, who experienced out-of-hospital CPA, and 26 (31.3\%) of these patients were discharged from hospital. Therefore, we conclude that the survival rate of $14.3 \%$ in our study is consistent with the previous study findings. The arrest being witnessed and the immediate initiation of CPR are related to both ROSC and a good neurological outcome 4, 10, 17-23. Unfortunately, bystander CPR is performed in only 15 to $40 \%$ of the pediatric out-of-hospital CPA cases. ${ }^{4,5,10}$ In a study conducted in Canada between 1991 and 2002, Gerein et al. ${ }^{8}$ reported 503 out-ofhospital CPA cases. Of these patients, $34 \%$ were witnessed, $80.7 \%$ were witnessed by a bystander, and $18.1 \%$ by EMS. Bystander CPR was performed in $32.4 \%$ of the cases. In another study carried out in USA between 2002 and 2003, Foltin et al. ${ }^{24}$ described 147 out-of-hospital CPA cases and reported the bystander CPR rate to be $30 \%$. In the study by Park et al. ${ }^{14}, 33.7 \%$ of the cases were witnessed and bystander CPR was performed in only $2.9 \%$ of these cases with a survival rate of $5 \%$. In our study, the witnessed arrests were at a rate of $75.8 \%(138 / 182)$; of these $67.4 \%$ were witnessed by a bystander, and the rate of CPR being performed by a bystander was $13.9 \% .{ }^{14}$ The ROSC was observed in $76.9 \%$ of the cases for whom bystander CPR was performed; however, the rate of discharge from hospital was $15.4 \%$. It was found that CPR carried out by the witness increased the ROSC rate; however, it did not improve the survival rate. When an arrest case is witnessed, the period of no-flow is shorter; moreover, early and efficient CPR increases the patient's probability of survival.

Ventricular rhythm is quite rarely observed in children; the initially identified rhythm in the arrest is usually asystole or PEA. ${ }^{9}$ In various studies, a VT/VF incidence of 4 to $8 \%$ was reported in pediatric out-of-hospital CPA cases. $5,7,8,12,14,15$ Similarly, the incidence was $2 \%$ in the study conducted by Foltin et al. ${ }^{24}$ and Park et al. ${ }^{14}$ also identified $2 \%$ incidence of a rhythm which could be shocked. In our study, the incidence of VT/VF was $2.2 \%$. These low $\mathrm{VT} / \mathrm{VF}$ rates are due to the causes of arrest being more likely related to respiratory and circulatory failure, rather than to any cardiac pathology.

Moreover, it is well-established that short duration of the arrest is critical for the survival rate. Schindler et al. ${ }^{27}$ reported patients who survived to hospital discharge had a significantly shorter interval between arrest and arrival at the hospital. In our study, the median (IQR) duration of arrest was found to be significantly lower in the patients in whom the ROSC was able to be achieved [5 (1-15) min], compared to those in whom the ROSC was unable to be achieved [15 (5-40) $\mathrm{min}](\mathrm{p}<0.001)$.

The duration of resuscitation being short in out-of-hospital CPA cases was found to be significant for ROSC. Schindler et al. ${ }^{27}$ also showed that the short resuscitation period in the emergency setting was an important indicator of survival. None of the patients with CPR duration of longer than 20 min were able to survive. Innes et al. ${ }^{30}$ also reported that none of the cases with in-hospital or out-of-hospital CPA, whose CPR duration was longer than 30 
min, survived. Abramson et al. ${ }^{31}$ reported that a delay time of $>6 \mathrm{~min}$. with subsequent CPR time of 6-15 min. until return of spontaneous circulation had a $19 \%$ survival with good neurological outcome. In a study conducted by Matos et al..$^{32}$ favorable neurological outcome was achieved in $11.0 \%$ of all children after CPR for $>15$ minutes and in $9.5 \%$ after 35 minutes. In our study, the ROSC was identified in $94.9 \%$ of the patients who underwent CPR for less than 20 minute. In cases where CPR lasts longer than $20 \mathrm{~min}, 5.7 \%$ were discharged from hospital; however, all of them were in a poor neurological state. We found that there was no statistically significant difference in comparison of arrest and duration of CPR in patients discharged home with good or poor neurological status. This result may be due to the small number of patients.

Nonetheless, there are some limitations to this study. First, it was conducted in only one geographical region of Turkey. Therefore, the results may not be applicable to other regions of the country. Second, some data were unable to be reached due to the retrospective design of the study. In non-witnessed CPA in particular, the reliability of the time of the arrest is controversial. Although in most of the cases etiology is clear, there are some cases where the cause of death can only be ascertained by autopsy. Third, due to the absence of emergency physicians in the ambulances, pediatric patients were unable to be intervened. We were also unable to capture the quality of CPR performed on the children in our study. Fourth, we determined the neurological outcome during discharge with a simple PCP score. Ideally, outcome would be assessed at follow-up visits at one year or longer with detailed neurobehavioral tests. Finally, we were unable to identify the initial cardiac arrest rhythm in all patients. In $12.6 \%$ patients, the initial rhythm data were missing and important data were not recorded. This may be due to the level of training of EMS staff.

In conclusion, despite the development of novel treatments and guidelines on out-of-hospital CPA arrests, the results are not still favorable for neurological outcomes and survival rates. Our study shows that ROSC rate is increased in witnessed arrests, shorter CPR time in under 20 minute arrests. Early intervention is important but survival rate can be expected to increase with the correct and effective intervention. For this reason, we think that everyone should be given basic life support education.

\section{Acknowledgement}

Thanks to "Ankara Pediatric Emergency Medicine and Pediatric Critical Care (A-PECC) Study Group" for their valuable contributions to the study.

\section{REFERENCES}

1. Committee PEM. The role of the emergency physician in the care of children. American College of Emergency Physicians. Pediatric Emergency Medicine Committee. Ann Emerg Med 1990; 19: 435-436.

2. Tibballs J, Kinney S. Reduction of hospital mortality and of preventable cardiac arrest and death on introduction of a pediatric medical emergency team. Pediatr Crit Care Med 2009; 10: 306-312.

3. Pruitt CM. When will we get there? The quandary of investigation in pediatric out-of-hospital cardiac arrest. Resuscitation 2015; 97: A3-A4.

4. Kitamura T, Iwami T, Kawamura T, et al. Conventional and chest-compression-only cardiopulmonary resuscitation by bystanders for children who have outof-hospital cardiac arrests: a prospective, nationwide, population-based cohort study. Lancet 2010; 375: $1347-1354$

5. Atkins DL, Everson-Stewart S, Sears GK, et al. Resuscitation Outcomes Consortium I Epidemiology and outcomes from out-of-hospital cardiac arrest in children: the Resuscitation Outcomes Consortium Epistry-Cardiac Arrest. Circulation 2009; 119: 14841491.

6. Bardai A, Berdowski J, van der Werf C, et al. Incidence, causes, and outcomes of out-of-hospital cardiac arrest in children. A comprehensive, prospective, populationbased study in the Netherlands. J Am Coll Cardiol 2011; 57: 1822-1828

7. Young KD, Gausche-Hill M, McClung CD, Lewis RJ. A prospective, population-based study of the epidemiology and outcome of out-of-hospital pediatric cardiopulmonary arrest. Pediatrics 2004; 114: 157-164.

8. Gerein RB, Osmond MH, Stiell IG, Nesbitt LP, Burns $\mathrm{S}$. What are the etiology and epidemiology of out-ofhospital pediatric cardiopulmonary arrest in Ontario, Canada? Acad Emerg Med 2006; 13: 653-658.

9. Atkins DL, Berger S. Improving outcomes from out-of-hospital cardiac arrest in young children and adolescents. Pediatr Cardiol 2012; 33: 474-483.

10. Donoghue AJ, Nadkarni V, Berg RA, et al. Out-ofhospital pediatric cardiac arrest: an epidemiologic review and assessment of current knowledge. Ann Emerg Med 2005; 46: 512-522.

11. Zuckerman GB, Gregory PM, Santos-Damiani SM Predictors of death and neurologic impairment in pediatric submersion injuries. The Pediatric Risk of Mortality Score. Arch Pediatr Adolesc Med 1998;152:134-140. 
12. Sirbaugh PE, Pepe PE, Shook JE, et al. A prospective, population-based study of the demographics, epidemiology, management, and outcome of out-ofhospital pediatric cardiopulmonary arrest. Ann Emerg Med 1999; 33: 174-184.

13. Young KD, Seidel JS. Pediatric cardiopulmonary resuscitation: a collective review. Ann Emerg Med 1999; 33: 195-205.

14. Park CB, Shin SD, Suh GJ, et al. Pediatric out-of-hospital cardiac arrest in Korea: A nationwide population-based study. Resuscitation 2010; 81: 512-517.

15. Deasy C, Bernard SA, Cameron P, et al. Epidemiology of paediatric out-of-hospital cardiac arrest in Melbourne, Australia. Resuscitation 2010; 81: 1095-1100.

16. Kitamura T, Kiyohara K, Nitta M, Nadkarni VM, Berg RA, Iwami T. Survival following witnessed pediatric out-of-hospital cardiac arrests during nights and weekends. Resuscitation 2014; 85: 1692-1698.

17. Hickey RW. Response to: Out-of-hospital pediatric cardiac arrest: an epidemiologic review and assessment of current knowledge. Ann Emerg Med 2006; 48: 219.

18. Hickey RW, Cohen DM, Strausbaugh S, Dietrich AM. Pediatric patients requiring CPR in the prehospital setting. Ann Emerg Med 1995; 25: 495-501.

19. Kuisma M, Alaspaa A. Out-of-hospital cardiac arrests of non-cardiac origin. Epidemiology and outcome. Eur Heart J 1997; 18: 1122-1128.

20. Rodriguez-Nunez A, Lopez-Herce J, Garcia C, Dominguez P, Carrillo A, Bellon JM. Spanish Study Group of Cardiopulmonary Arrest in C. Pediatric defibrillation after cardiac arrest: initial response and outcome. Crit Care 2006; 10: 113.

21. Lopez-Herce J, Garcia C, Dominguez P, et al. Spanish Study Group of Cardiopulmonary Arrest in C. Characteristics and outcome of cardiorespiratory arrest in children. Resuscitation 2004; 63: 311-320.

22. Lopez-Herce J, Garcia C, Dominguez P, et al. Spanish Study Group of Cardiopulmonary Arrest in C. Outcome of out-of-hospital cardiorespiratory arrest in children. Pediatr Emerg Care 2005; 21: 807-815.
23. Lopez-Herce J, Garcia C, Rodriguez-Nunez A, et al. Spanish Study Group of Cardiopulmonary Arrest in C . Long-term outcome of paediatric cardiorespiratory arrest in Spain. Resuscitation 2005; 64: 79-85.

24. Foltin GL, Richmond N, Treiber M, et al. Pediatric prehospital evaluation of NYC cardiac arrest survival (PHENYCS). Pediatr Emerg Care 2012; 28: 864-868.

25. Tijssen JA, Prince DK, Morrison LJ, et al. Resuscitation Outcomes C. Time on the scene and interventions are associated with improved survival in pediatric out-ofhospital cardiac arrest. Resuscitation 2015; 94: 1-7.

26. Cunningham LM, Mattu A, O'Connor RE, Brady WJ. Cardiopulmonary resuscitation for cardiac arrest: the importance of uninterrupted chest compressions in cardiac arrest resuscitation. Am J Emerg Med 2012; 30: $1630-1638$

27. Schindler MB, Bohn D, Cox PN, et al. Outcome of out-of-hospital cardiac or respiratory arrest in children. N Eng J Med 1996; 335: 1473-1479.

28. Kendirli T, Erkek N, Koroglu T, et al. Cardiopulmonary resuscitation in children with in-hospital and out-ofhospital cardiopulmonary arrest: Multicenter study from Turkey. Pediatr Emerg Care 2015; 31: 748-752.

29. Ahn JY, Lee MJ, Kim H, Yoon HD, Jang HY. Epidemiological and survival trends of pediatric cardiac arrests in emergency departments in Korea: Acrosssectional, nationwide report. J Korean Med Sci 2015; 30: $1354-1360$

30. Innes PA, Summers CA, Boyd IM, Molyneux EM. Audit of paediatric cardiopulmonary resuscitation. Arch Dis Child 1993; 68: 487-491.

31. Abramson NS, Safar P, Detre KM, et al. Neurologic recovery after cardiac arrest: Effect of duration of ischemia. Crit Care Med 1985; 13: 930-931.

32. Matos MR, Watson RS, Nadkarni VM, et al. Duration of cardiopulmonary resuscitation and illness category impact survival and neurologic outcomes for in-hospital pediatric cardiac arrests. Circulation 2013; 127: 442451. 